\section{Transtornos da Personalidade}

Mario Rodrigues Louzã Neto, Táki Athanássios Cordás e colaboradores. Transtornos da Personalidade. $1^{\mathrm{a}} \mathrm{ed}$. Porto Alegre: Artmed, 2011.

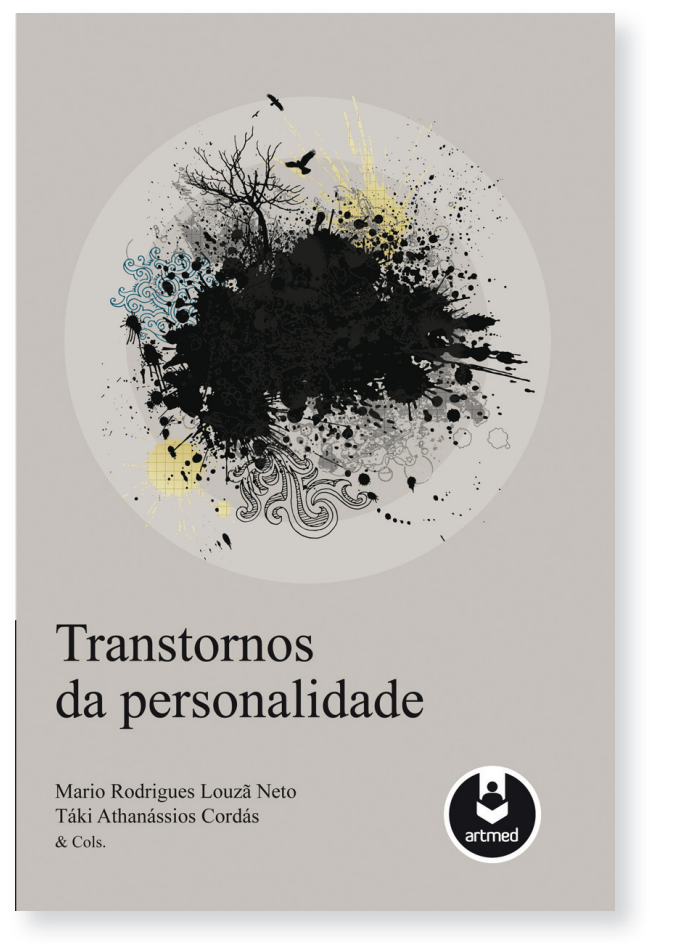

Os transtornos de personalidade são condições psiquiátricas complexas e possivelmente ainda pouco entendidas diante dos conhecimentos e possibilidades da medicina atual. Possuem prevalências significativas e alguns deles estão claramente relacionados com os piores prognósticos de transtornos psiquiátricos do eixo I, elevado índice de suicídios, doenças clínicas e problemas familiares. Suas apresentações são bastante heterogêneas, não só entre os 3 clusters, mas dentro de cada uma das 11 possibilidades diagnósticas. Nas últimas décadas, a genética, a neurobiologia, a farmacologia e os estudos de imagem somamse à psicodinâmica na busca de uma melhor compreensão dos transtornos de personalidade.

Os psiquiatras Mario Louzã e Táki Cordás, professores, pesquisadores e já editores de vários outros livros importantes, reuniram uma série de profissionais envolvidos no tema e organizaram o livro Transtornos da Personalidade.

O livro inicia, na Grécia antiga, com uma retrospectiva histórica das idéias iniciais sobre personalidade e características individuais, discorrendo sobre o pensamento de filósofos, dos antigos alienistas, de psicanalistas e de psiquiatras. Os primeiros capítulos são dedicados à epidemiologia, aspectos genéticos e neurobiologia, escritos a partir de artigos recentes e resumindo o que há de mais novo em estudos nestas áreas.

Um dos pontos fortes do livro é a maneira pela qual são discutidos alguns tópicos em conjunto - de uma forma original - e que não levaria a uma leitura tão objetiva e clara se fossem lidos, como o são editados, de forma separada, em artigos de revistas. Neste formato, alguns capítulos merecem destaque: Transtornos de Conduta na Infância e Transtorno de Personalidade Antissocial; Personalidade, Transtornos de Personalidade e Esquizofrenia; Transtornos da Personalidade e Transtornos Dissociativos (ou conversivos); e Transtornos Somatoformes e Personalidade.

Além de capítulos sobre comorbidade/interface entre os transtornos de personalidade e transtornos de ansiedade, de humor e de dependência química, também aparecem textos específicos sobre a relação entre os transtornos de personalidade e obesidade, transtornos alimentares, de déficit de atenção e transtornos da sexualidade.

É importante salientar que vários capítulos do livro discorrem sobre personalidade borderline ou limítrofe: a visão psicanalítica sobre esse transtorno específico de personalidade, a importância do vinculo terapêutico com esses pacientes, as possibilidades farmacológicas disponíveis e uma idéia a respeito da terapia comportamental dialética. O livro traz, também, elementos para que o leitor possa refletir sobre a freqüente e desafiadora pergunta de alta relevância clínica: qual o limite entre transtorno borderline de personalidade e transtorno de humor bipolar?

Pessoalmente, gostei muito do último capítulo, que cumpre o caminho da ciência em não encerrar a reflexão acerca de um assunto, mas sim em abrir uma (muitas) idéia(s). Este livro discute os transtornos de personalidade desde a perspectiva do risco do julgamento moral a que seus portadores estão submetidos até a possibilidade epigenética, de um modo integrativo e não dissociado. Os autores e seus colaboradores, de fato, realizaram um excelente trabalho e penso que essa obra, realizada no Brasil, é uma boa sugestão de leitura aos que buscam uma expansão do conhecimento no campo dos transtornos de personalidade.

\section{Lucas Lovato}

Professor e pesquisador do Programa de Pesquisa e Ensino dos Transtornos de Personalidade da residência em psiquiatria do Hospital Psiquiátrico São Pedro, Porto Alegre, RS. 